\title{
Information and Communication Technologies (ICT) to Improve Prescription Appropriateness and Therapy Adherence in the Multi-morbid Elderly
}

\author{
Alberto Borghese \\ Applied Intelligent Systems Laboratory, Department of Computer Science - University of Milan, Italy.
}

Received: 14/09/2015

Accepted: 19/09/2015

Published: $24 / 09 / 2015$

How to cite this article: Borghese A. Information and communication technologies (ICT) to improve prescription appropriateness and therapy adherence in the multi-morbid elderly. EJCRIM 2015;2:DOI: 10.12890/2015_S1SP07

Conflicts of Interests: The authors declare that they have no conflicts of interest in this research.

Acknowledgements: This abstract has been presented as a lecture at $2^{\text {nd }}$ International Seminar REPOSI: Targeting the burden of polypharmacy in the elderly.

This article is licensed under a Commons Attribution Non-Commercial 4.0 License

Multimorbidity patients pose severe challenges to which information and communication technology (ICT) can help patients and doctors to answer with effective and efficient care.

We first examine the role that can be played by Artificial Intelligence based systems built on effective knowledge representation to coordinate the activity of the different specialists. Such systems have also the potentiality to build a collective knowledge that can be delivered back, for instance, in the form of personalized guidelines for multimorbidity.

Artificial Intelligence systems can be integrated by pervasive physiological sampling that can be carried out safely at home. This can provide an updated clear picture of patient status. Physiological data can be uploaded to care centers that are such enabled to monitor the patient remotely; these data can also be used to plan, coordinate and tune clinical intervention.

Such systems can be complemented by education relying on multi-media digital content and gamification. A few examples on this will be portrayed.

Finally, a few ideas on how to increase the compliance of patients, providing personalized memos through mobile phone technology will also be presented. 